\title{
DESEMPENHO AGRONÔMICO E ESTADO NUTRICIONAL DO CAPIM MOMBAÇA FERTIRRIGADO COM ÁGUAS RESIDUÁRIAS DE CURTUME
}

\author{
Pedro Rodrigues de Oliveira ${ }^{1}$, Antonio Teixeira de Matos $^{2}$, Paola Alfonsa Vieira Lo Monaco ${ }^{3}$
}

\section{RESUMO}

Objetivou-se, com a realização deste trabalho, avaliar a produtividade e o estado nutricional do capim mombaça (Panicum Maximum cv. Mombaça) quando fertirrigado com a aplicação de diferentes doses de água residuária de curtume (ARC). Com base na composição química da água residuária foram estabelecidas as taxas de aplicação da ARC: $\mathrm{T}_{1}: 0 ; \mathrm{T}_{2}: 1,5 ; \mathrm{T}_{3}: 3,0 ; \mathrm{T}_{4}: 5,0 ; \mathrm{T}_{5}: 10$ e $\mathrm{T}_{6}: 15 \mathrm{~kg} \mathrm{ha}^{-1}$ de crômio. De acordo com os resultados obtidos, pôde-se concluir que a aplicação da ARC foi responsável pelo aumento no teor de proteína bruta do capim nos dois primeiros cortes e também na produtividade de matéria seca. Tanto a produtividade de matéria seca quanto a de proteína bruta foram maiores no corte 2, sendo estimados os maiores valores quando da aplicação das doses de $9,02 \mathrm{~kg} \mathrm{ha}^{-1} \mathrm{de} \mathrm{Cr}$ (2.734 $\mathrm{m}^{3} \mathrm{ha}^{-1}$ de ARC) e 10,08 $\mathrm{kg} \mathrm{ha}^{-1}$ de $\mathrm{Cr}$ (3.055 $\mathrm{m}^{3} \mathrm{ha}^{-1}$ de ARC), respectivamente. O aumento na dose de ARC proporcionou valores decrescentes na concentração potássio e crescentes na de sódio nas folhas do capim mombaça. Em relação ao comportamento do metal crômio, não foi observada influência dos tratamentos na sua concentração nas folhas. Em vista de se utilizar muito $\mathrm{NaCl}$ na salga das peles, o aumento na concentração de sódio nas plantas é aparentemente problema maior do que propriamente o proporcionado pelo crômio.

Palavras-Chave: curtumes, crômio, forrageira.

\section{ABSTRACT \\ AGRONOMIC PERFORMANCE AND NUTRITIONAL STATUS OF MOMBASA GRASS FERTIGATED WITH TANNERY WASTEWATER}

The objective of this study was to assess the productivity and nutritional status of Mombasa grass (Panicum maximum cv. Mombasa) when fertigated with the application of different doses of tannery wastewater (ARC). Based on the chemical composition of the wastewater, the following ARC application rates were established: $\mathrm{T}_{1}: 0 ; \mathrm{T}_{2}: 1.5 ; \mathrm{T}_{3}$ : 3.0; $\mathrm{T}_{4}: 5.0 ; \mathrm{T}_{5}: 10$ and $\mathrm{T}_{6}: 15 \mathrm{~kg} \mathrm{ha}^{-1}$ of chromium. According to the results obtained, it was concluded that the application of wastewater was responsible for the increased crude protein content of grass in the first two cuts and also the dry matter yield. Both the productivity of dry matter as well as crude protein were higher in cut 2 , where the highest values were estimated when applying the doses of $9.02 \mathrm{~kg} \mathrm{ha}^{-1}$ of $\mathrm{Cr}\left(2,734 \mathrm{~m}^{3} \mathrm{ha}^{-1} \mathrm{ARC}\right)$ and $10.08 \mathrm{~kg} \mathrm{ha} \mathrm{g}^{-1}$ of $\mathrm{Cr}\left(3,055 \mathrm{~m}^{3} \mathrm{ha}^{-1} \mathrm{ARC}\right)$, respectively. Increase in the ARC dose resulted in decreasing potassium concentrations and increases in sodium in the leaves of Mombasa grass. In relation to the behavior of chromium metal, no influence of the treatments was observed on its concentration in the leaves of Mombasa grass. In the specific case of the wastewater studied, because a large $\mathrm{NaCl}$ content is used for salting the skins, the increase in sodium concentrations in the plants is apparently a larger problem than that resulting from chromium.

Keywords: tanning, chromium, forage.

Recebido para publicação em 20/01/2012. Aprovado em 06/12/2012.

1 - Engenheiro Ambiental, M.S. em Eng. Agrícola. Inst. Natureza do Tocantins - NATURATINS. E-mail: pedrooliveira96@yahoo.com.br.

2 - Engenheiro Agrícola, D.S. em Solos e Nutrição de Plantas; Professor Associado DEA/UFV. E-mail: atmatos@ufv.br.

3 - Engenheira Agrícola, D.S. em Engenharia Agrícola; Professora do IFET - Centro Serrano-ES. E-mail: paolalomonaco2004@yahoo.com.br. 


\section{INTRODUÇ̃̃O}

Em estados onde a atividade econômica está baseada na agropecuária, como é o caso do Tocantins, a agroindústria de processamento de peles é uma das mais importantes, aumentando o valor agregado ao couro, sendo um setor econômico responsável pela geração de grande quantidade de empregos e receita para o Estado.

Um dos grandes problemas ambientais associados aos curtumes é a poluição causada pelos seus resíduos, os quais possuem elevadas cargas orgânicas e inorgânicas. Dentre os poluentes inorgânicos presentes, o crômio é o que maior preocupação desperta, notadamente quando presente na forma hexavalente, já que, de acordo com Conceição et al. (2007) é um cátion tóxico, sendo considerado mutagênico e carcinogênico. Essa forma iônica é também muito solúvel e, por esta razão, se movimenta em velocidades próximas à da água em percolação, podendo vir a contaminar águas subterrâneas. O crômio trivalente, ao contrário, apresenta toxicidade relativamente baixa, permanecendo imóvel em ambientes moderadamente alcalinos e levemente ácidos (FACHIN et al., 2006). Embora nos despejos de curtumes predominem os compostos de crômio trivalente, dependendo de algumas variáveis do corpo receptor, a oxidação de $\mathrm{Cr}^{3+}$ a $\mathrm{Cr}^{6+}$ pode ser favorecida, colocando em risco a fauna, a flora e a população que utilizam estas águas (JORDÃO et al., 1999). No solo, a oxidação do $\mathrm{Cr}^{+3} \mathrm{a} \mathrm{Cr}^{+6}$ não é uma reação comum, ocorrendo, entretanto, em condições de adequado conteúdo de água e na presença de altas concentrações de manganês facilmente redutível (AQUINO NETO; CAMARGO, 2000).

Uma medida de controle ambiental que vem sendo praticada atualmente, em grande escala, no gerenciamento de efluentes de empreendimentos agroindustriais é a disposição no solo, por intermédio da fertirrigação. Essa prática tem sido cada vez mais frequente em diversos países e também no Brasil, trazendo como benefício o aproveitamento, por parte da cultura, dos nutrientes presentes no efluente, possibilitando a preservação dos cursos d'água, já que deixarão de receber essas cargas poluentes. De acordo com Lo Monaco et al. (2009), se realizada de forma adequada, a fertirrigação pode possibilitar aumento na produtividade, reduzir a poluição ambiental, além de promover melhoria nas características químicas, físicas e biológicas do solo. Erthal et al. (2010) ressaltam que o referencial para definição das taxas de aplicação não deve ser lâminas calculadas em função da evapotranspiração da cultura e, sim, da capacidade do sistema solo-planta em absorver o resíduo aplicado sem comprometer a qualidade do solo, da planta nem das águas subterrâneas. De acordo com os mesmos autores, em geral, os teores de nitrogênio, elementos fitotóxicos, metais pesados e a salinidade, têm sido utilizados como referenciais na determinação da lâmina a ser aplicada na fertirrigação, devendo-se tomar por base o componente de maior concentração na água. No caso da água residuária de curtume, tornase necessário tomar por base o elemento crômio, metal pesado reconhecidamente preocupante, por possibilitar a contaminação do solo e da água subterrânea além de toxicidade para as plantas.

$\mathrm{Na}$ escolha de plantas forrageiras para fins de aplicação de águas residuárias por disposição no solo, devem-se preferir as perenes, com alta capacidade de extração de nutrientes e produção de matéria seca, que permitam cortes frequentes e sucessivos ao longo da maior parte do ano, que cubram bem o solo e sejam palatáveis aos animais; outras características desejáveis, são: adaptar-se às condições de clima e solo locais, apresentar baixa susceptibilidade a pragas e doenças e tolerância à salinidade e toxicidade a íons específicos (ERTHAL et al., 2010).

Nesse contexto, optou-se por trabalhar com o capim mombaça (Panicum maximum), considerando que é uma gramínea cujas exigências edafoclimáticas correspondem às existentes na região de Palmas-TO, tais como solos profundos, bem drenados, clima quente e precipitação anual superior a $1.000 \mathrm{~mm}$. Por ser uma espécie exigente em solo fértil(MINGOTTE et al., 2011), torna-se interessante utilizá-la para fins de fertirrigação com águas residuárias ricas em material orgânico e inorgânico, como as águas residuárias de curtume. Além disso, a cultivar mombaça tem alta produtividade e valor nutritivo (GARCIA et al., 2011), apresenta elevada produção de biomassa de folhas verdes, já que possui maior proporção de folhas (RIBEIRO et al.,

\section{REVENG}

$$
\text { 173-186p. }
$$

ENGENHARIA NA AGRICULTURA, VIÇOSA - MG, V.21 N.2, MARÇO / AbRIL 2013 
2009; GARCIA et al., 2011), destacando-se também por apresentar menor estacionalidade de produção (MULLER et al., 2002).

Dessa forma, objetivou-se, com a realização desse trabalho, avaliar o desempenho agronômico e o estado nutricional do capim mombaça (Panicum Maximum cv. Mombaça) quando fertirrigado com a aplicação de diferentes doses de águas residuárias de curtume (ARC).

\section{MATERIAL E MÉTODOS}

O experimento foi implantado e conduzido na área experimental do Departamento de Recursos Hídricos/Engenharia Agrícola do CEULPULBRA, em Palmas-TO, em casa de vegetação telada, não climatizada.

O solo utilizado no experimento foi coletado na camada arável $(0-20 \mathrm{~cm})$ numa área de cerrado virgem, portando sem registro de utilização agrícola anterior. $\mathrm{O}$ solo da área foi classificado como Latossolo Vermelho distrófico, segundo o sistema de classificação de solos da Empresa Brasileira de Pesquisa Agropecuária - EMBRAPA (1997). O material de solo foi coletado, de forma aleatória, em área de 0,50 ha, sendo as amostras simples posteriormente misturadas, formando uma amostra composta.

Após a coleta, as amostras foram encaminhadas ao Laboratório de Fertilidade do Solo e Física do Solo do DPS/UFV, respectivamente, para análises químicas e físicas, obedecendo-se metodologia proposta pela EMBRAPA (1997). No laboratório, foram determinadas as seguintes variáveis: $\mathrm{pH}$ em água, matéria orgânica, nitrogênio total, fósforo, crômio e potássio disponíveis, cálcio, magnésio e alumínio trocáveis; além da acidez potencial (Quadro 1).

A água residuária utilizada para fertirrigação das plantas foi proveniente de um curtume no qual ocorre o processamento de peles em nível wet blue, localizado no município de Porto Nacional, TO. A água residuária do curtume (ARC) foi armazenada em um reservatório de PVC, com capacidade de $0,35 \mathrm{~m}^{3}$, instalado próximo ao local do experimento e ao abrigo da luz.

O campim mombaça (Panicum maximum cv. Mombaça) foi escolhido para esse trabalho em razão de exigir solo fértil, profundo, bem drenado, clima quente e precipitação anual superior a 1.000 $\mathrm{mm}$, tal como ocorre na região de Tocantins, podendo ser boa opção de cultivo em áreas onde é aplicada a ARC.

Para caracterização daáguaresiduária, as análises foram realizadas nos Laboratórios de Qualidade da Água e de Química dos Resíduos do Departamento de Engenharia Agrícola da Universidade de ViçosaMG, em conformidade com a metodologia descrita no Standard Methods for the Examination of Water and Wastewater (APHA et al., 2005). No Quadro 2 estão apresentados os resultados das análises físicas, químicas, bioquímicas e físico-químicas, bem como as respectivas metodologias utilizadas.

O solo foi acondicionado em vasos de $5 \mathrm{~L}$, tendo seu pH corrigido até 6,0 , com a adição de calcário dolomítico (PRNT 85\%), na proporção de 2,5 t ha${ }^{1}$. A correção da fertilidade foi utilizando-se adubo mineral de formulação NPK 4-14-8, na proporção de $50 \mathrm{~kg} \mathrm{ha}^{-1}$, conforme orientações do órgão de extensão rural do Estado do Tocantins. O plantio do capim mombaça foi feito por semente, utilizandose um total, aproximado, de 30 sementes por vaso.

Quadro 1. Características químicas do solo utilizado no experimento

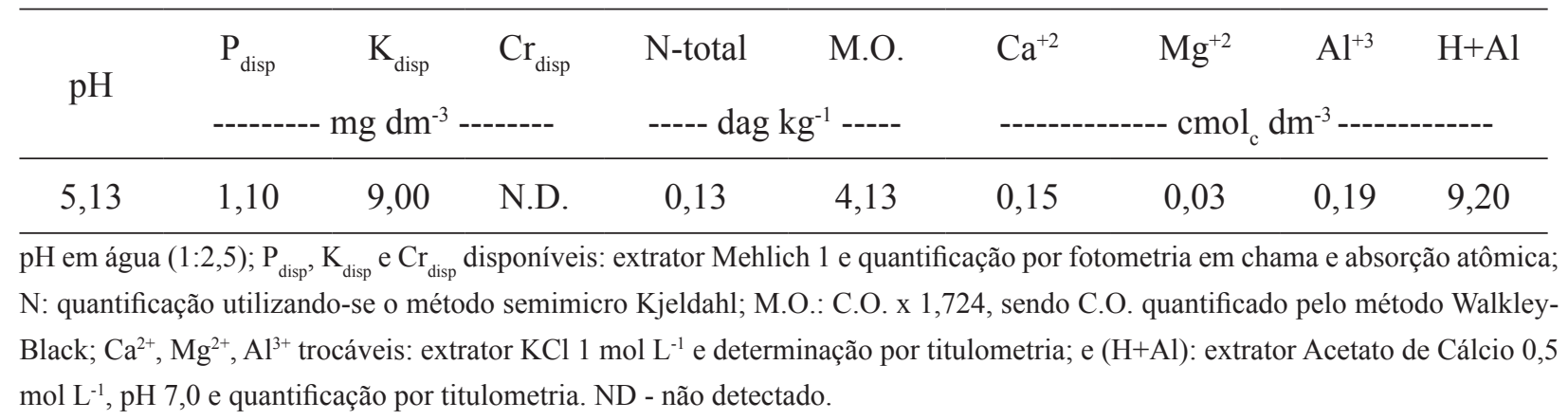


Quadro 2. Resultado das análises físicas, químicas, bioquímicas e físico-químicas da água residuária de curtume

\begin{tabular}{lcc}
\hline Variáveis & Resultado & Metodologia \\
\hline $\mathrm{pH}$ & 9,04 & Peagâmetro de bancada \\
\hline Cond. Elétrica & $21,89 \mathrm{dS} \mathrm{m}^{-1}$ & Condutivímetro de bancada \\
\hline $\mathrm{DQO}$ & $9.240 \mathrm{mg} \mathrm{L}^{-1}$ & Método de oxidação química em refluxo aberto \\
\hline $\mathrm{DBO}$ & $5.028 \mathrm{mg} \mathrm{L}^{-1}$ & $\begin{array}{c}\text { Quantificação do oxigênio dissolvido pelo método } \\
\text { iodométrico (Processo Winkler) }\end{array}$ \\
\hline $\mathrm{N}_{\text {Total }}$ & $1.367 \mathrm{mg} \mathrm{L}^{-1}$ & Processo Semimicro Kjeldahl \\
\hline $\mathrm{N}_{\text {Amon }}$ & $1.192 \mathrm{mg} \mathrm{L}^{-1}$ & Processo Semimicro Kjeldahl sem digestão \\
\hline $\mathrm{P}_{\text {Total }}$ & $2,00 \mathrm{mg} \mathrm{L}^{-1}$ & Fotometria de chama \\
\hline $\mathrm{Ca}_{\text {Total }}$ & $153 \mathrm{mg} \mathrm{L}^{-1}$ & \\
$\mathrm{Mg}_{\text {Total }}$ & $275 \mathrm{mg} \mathrm{L}^{-1}$ & \\
$\mathrm{~K}_{\text {Total }}$ & $52 \mathrm{mg} \mathrm{L}^{-1}$ & \\
$\mathrm{Na}_{\text {Total }}$ & $9.812 \mathrm{mg} \mathrm{L}{ }^{-1}$ & \\
\hline $\mathrm{Cr}_{\text {Total }}$ & $3,40 \mathrm{mg} \mathrm{L}^{-1}$ & \\
$\mathrm{Al}_{\text {Total }}$ & $\mathrm{ND}$ & \\
$\mathrm{Fe}_{\text {Total }}$ & $\mathrm{ND}$ & \\
$\mathrm{Cu}_{\text {Total }}$ & $\mathrm{ND}$ & \\
$\mathrm{Mn}_{\text {Total }}$ & $\mathrm{ND}$ & \\
$\mathrm{Zn}_{\text {Total }}$ & $\mathrm{ND}$ & \\
$\mathrm{Cd}_{\text {Total }}$ & $\mathrm{ND}$ & \\
$\mathrm{Pb}_{\text {Total }}$ & Espectrofotometria por absorção atômica \\
$\mathrm{Ni}_{\text {Total }}$ & & \\
\hline $\mathrm{ND}-$ não detectado. & \\
\end{tabular}

Quadro 3. Doses de elementos químicos aplicadas ao solo, em $\mathrm{kg} \mathrm{ha}^{-1}$, de acordo com as lâminas de água residuária de curtume nele dispostas

\begin{tabular}{|c|c|c|c|c|c|}
\hline \multirow{2}{*}{ Nutrientes } & \multicolumn{5}{|c|}{ Lâminas (mm) } \\
\hline & 44 & 103 & 147 & 294 & 441 \\
\hline $\mathrm{K}$ & 22,8 & 54,0 & 76,4 & 153,0 & 229,4 \\
\hline $\mathrm{N}$ & 600,6 & $1.420,9$ & $2.009,1$ & $4.022,3$ & $6.031,4$ \\
\hline $\mathrm{P}$ & 0,9 & 2,1 & 2,9 & 5,9 & 8,8 \\
\hline $\mathrm{Ca}$ & 67,3 & 159,0 & 224,9 & 450,2 & 675,1 \\
\hline $\mathrm{Mg}$ & 120,8 & 285,8 & 404,2 & 809,2 & $1.213,3$ \\
\hline $\mathrm{Cr}$ & 1,5 & 3,5 & 5,0 & 10,0 & 15,0 \\
\hline $\mathrm{Na}$ & $4.311,3$ & $10.198,5$ & $14.420,6$ & $28.871,1$ & $43.290,9$ \\
\hline
\end{tabular}

\section{REVENG}

173-186p. Engenharia NA AGRICULTURA, VIÇOSA - MG, V.21 N.2, MARÇO / ABRIL 2013 
Decorrido um período de 18 dias após o plantio, efetuou-se um desbaste nos vasos, deixando-se 12 plantas em cada um deles. Os vasos foram dispostos em fileiras distanciadas de 1,0 m entre elas, sendo a distância entre vasos de $0,5 \mathrm{~m}$.

Com base na composição química da água residuária (Quadro 2), foram estabelecidas as taxas de aplicação da ARC: $\mathrm{T}_{1}: 0 \mathrm{~kg} \mathrm{ha}^{-1}$ de crômio, $\mathrm{T}_{2}$ : $1,5 \mathrm{~kg} \mathrm{ha}^{-1}$ de crômio, $\mathrm{T}_{3}: 3,0 \mathrm{~kg} \mathrm{ha}^{-1}$ de crômio, $\mathrm{T}_{4}$ : $5,0 \mathrm{~kg} \mathrm{ha}^{-1}$ de crômio, $\mathrm{T}_{5}: 10 \mathrm{~kg} \mathrm{ha}^{-1}$ de crômio e $\mathrm{T}_{6}: 15 \mathrm{~kg} \mathrm{ha}^{-1}$ de crômio. Com base nessas doses, as lâminas de água residuária aplicadas foram 44, 103, 147, 294 e $441 \mathrm{~mm}$, respectivamente para os tratamentos $\mathrm{T}_{2}, \mathrm{~T}_{3}, \mathrm{~T}_{4}, \mathrm{~T}_{5}$ e $\mathrm{T}_{6}$. No Quadro 3 estão apresentadas as cargas de elementos químicos aplicadas ao solo, de acordo com as doses de ARC aplicadas.

A aplicação da água residuária foi feita utilizando-se de um regador manual, de forma a se propiciar o contato da água residuária com as folhas do capim, simulando-se a aplicação por aspersão. A primeira dose de água residuária foi aplicada 20 dias após o plantio do capim e as aplicações subsequentes foram feitas uma vez por semana.

Para definir a quantidade de água a ser aplicada e garantir o conteúdo de água adequado para atingir a capacidade de campo, considerou-se um volume de $50 \%$ de poros no solo de cada vaso e que a capacidade de campo do solo correspondia a $50 \%$ de ocupação desses poros com água. Assim, a determinação foi feita por meio da pesagem de todos os vasos, anotando-se a massa inicial de cada um. Em seguida, adicionou-se 1,25 litros de água de rede de abastecimento (proveniente de um poço tubular profundo o qual abastece todas as instalações do Centro Universitário Luterano de Palmas), objetivando-se o preenchimento de 50\% do volume de poros do vaso. Depois de efetuado esse procedimento, pesou-se, novamente, os vasos, determinando-se a massa final de cada vaso. Dessa forma, por meio de pesagem, passou-se a controlar e a efetuar a reposição de água da rede de abastecimento nos vasos, sempre com o intuito de manter o solo com conteúdo de água próximo ao da capacidade de campo. A reposição de água nos vasos foi feita duas vezes ao dia, pela manhã e à tarde, porém nos meses de agosto e setembro, devido à baixa umidade relativa do ar, período em que a quantidade evapotranspirada era muito grande, foi necessária reposição de água, também, ao meio dia.

Nos vasos submetidos aos tratamentos $T_{2}, T_{3}$, $\mathrm{T}_{4}, \mathrm{~T}_{5}$ e $\mathrm{T}_{6}$ foram aplicados, respectivamente, os seguintes volumes totais de água residuária: 1,45 ; 3,43; 4,85; 9,71 e 14,56 L. Esses volumes foram divididos em 10 aplicações semanais, durante o período de 24 de junho a 07 de setembro de 2009. As menores lâminas de $\operatorname{ARC}(44,103$ e 147 $\mathrm{mm}$ ), foram aplicadas de uma só vez, enquanto as maiores lâminas (294 e $441 \mathrm{~mm}$ ) foram aplicadas em duas e três vezes respectivamente, ao longo do mesmo dia.

O primeiro corte do capim ocorreu após a quarta aplicação da ARC, o segundo corte ocorreu após a sétima aplicação e o último corte, dois dias após a décima aplicação.

Após cada corte, as amostras de capim foram pesadas e, em seguida, levadas para secagem em estufa com recirculação de ar e sob temperatura de $65{ }^{\circ} \mathrm{C}$, onde permaneceram por 72 horas. Decorrido esse tempo, o capim foi novamente pesado, sendo posteriormente retirada uma nova amostra de aproximadamente de $5 \mathrm{~g}$ de cada material, que foi moída, acondicionada em saco plástico e armazenada para posterior quantificação do conteúdo de matéria seca e realização da análise nutricional $(\mathrm{N}, \mathrm{P}, \mathrm{K}, \mathrm{Na}$ e $\mathrm{Cr}$ ). A quantificação de N-total foi feita pelo método semimicro Kjeldhal e, após digestão nítrico-perclórico das amostras, a de P-total por espectrofotometria, e $\mathrm{K}$ e $\mathrm{Na}$, por fotometria de chama e a de $\mathrm{Cr}$ em espectrofotometro por absorção atômica. As análises laboratoriais foram realizadas em conformidade com recomendações de Kiehl (1998), sendo efetuadas no laboratório de Solos e Resíduos Sólidos do Departamento de Engenharia Agrícola da UFV.

$\mathrm{O}$ delineamento experimental usado foi o inteiramente casualizado (DIC), com quatro repetições e cinco doses de crômio. $\mathrm{Na}$ análise estatística, os dados foram analisados utilizandose o programa de estatística SAEG 9.1 (UNIVERSIDADE FEDERAL DE VIÇOSA UFV, 2006) para realização da análise de variância (ANOVA). Posteriormente, as médias foram comparadas utilizando-se o teste de Dunnett, com 
$5 \%$ de significância, sendo ajustados modelos de regressão para massa verde e massa seca como função da dose de $\mathrm{Cr}$, estabelecendo-se um nível de significância de $5 \%$ de probabilidade para os coeficientes.

\section{RESULTADOS E DISCUSSÃO}

No Quadro 4 estão apresentados os valores médios de produtividade de matéria seca e proteína bruta e das concentrações de macronutrientes e sódio do capim mombaça, em função das doses de aplicação da ARC.

Com base na análise de variância, verifica-se que a aplicação de ARC proporcionou maior ( $\mathrm{P}$ $<0,05)$ produtividade de matéria seca do capim mombaça que no tratamento controle, o qual não recebeu a ARC (Quadro 4).

A análise de regressão, realizada para que se pudesse verificar o comportamento da produtividade de matéria seca em função da dose de $\mathrm{Cr}$ aplicada, indicou resposta quadrática para esta variável (Figura 1), tendo as doses estimadas de aplicação de $3.055 \mathrm{~m}^{3} \mathrm{ha}^{-1}\left(10,08 \mathrm{~kg} \mathrm{ha}^{-1} \mathrm{de}\right.$ Cr) no corte 1 , de $2.734 \mathrm{~m}^{3} \mathrm{ha}^{-1}\left(9,02 \mathrm{~kg} \mathrm{ha}^{-1} \mathrm{de}\right.$ Cr) no corte 2 e de $3.375 \mathrm{~m}^{3} \mathrm{ha}^{-1}\left(12,46 \mathrm{~kg} \mathrm{ha}^{-1} \mathrm{de}\right.$ $\mathrm{Cr}$ ) no corte 3 , as que proporcionaram as maiores produtividades de matéria seca.

Quadro 4. Valores médios de produtividade de matéria seca e proteína bruta e das concentrações de macronutrientes e sódio do capim mombaça, em função das doses de aplicação da ARC

\begin{tabular}{|c|c|c|c|c|c|c|c|}
\hline \multirow{2}{*}{$\begin{array}{l}\text { Tratamentos } \\
\left(\mathrm{kg} \mathrm{ha}^{-1} \text { de } \mathrm{Cr}\right)\end{array}$} & \multirow{2}{*}{$\begin{array}{c}\text { Dose de } \\
\text { ARC } \\
\left(\mathrm{m}^{3} \mathrm{ha}^{-1}\right)\end{array}$} & Massa seca & $\begin{array}{c}\text { Proteína } \\
\text { bruta }\end{array}$ & $\mathrm{N}$ & $\mathrm{P}$ & $\mathrm{K}$ & $\mathrm{Na}$ \\
\hline & & \multicolumn{2}{|c|}{---------- kg ha'-1 --------- } & \multicolumn{4}{|c|}{-------------- dag kg-1 -------------- } \\
\hline \multicolumn{8}{|c|}{$1^{\circ}$ CORTE } \\
\hline 0 (controle) & 0,0 & $4.336,4$ & 210,3 & 0,76 & 1,32 & 0,69 & 0,09 \\
\hline 1,5 & 454,5 & $8.106,1$ & $52,8 *$ & 1,05 & $1,01^{*}$ & 0,45 & 0,20 \\
\hline 3,0 & 909,1 & $14.806,1 *$ & $1.072,0^{*}$ & $1,13^{*}$ & $0,82 *$ & 0,55 & $0,38^{*}$ \\
\hline 5,0 & $1.515,2$ & $14.103,0 *$ & $1.150,8^{*}$ & $1,27 *$ & $0,73^{*}$ & 0,42 & $0,69 *$ \\
\hline 10,0 & $3.030,3$ & $16.342,4$ & $2.505,3^{*}$ & $2,41^{*}$ & $0,82 *$ & 0,43 & $0,85^{*}$ \\
\hline 15,0 & $4.545,5$ & $15.533,3 *$ & $2.407,7 *$ & $2,41 *$ & $0,91 *$ & 0,45 & $1,13^{*}$ \\
\hline \multicolumn{8}{|c|}{$2^{\circ}$ CORTE } \\
\hline 0 (controle) & 0,0 & $2.409,1$ & 103,6 & 0,66 & 1,07 & 0,75 & 0,06 \\
\hline 1,5 & 454,5 & $10.948,5^{*}$ & $739,0^{*}$ & $1,03 *$ & $0,76^{*}$ & 0,65 & $0,28^{*}$ \\
\hline 3,0 & 909,1 & $16.403,0 *$ & $1.502,5^{*}$ & $1,40 *$ & $0,65^{*}$ & 0,53 & $0,57 *$ \\
\hline 5,0 & $1.515,2$ & $16.630,3 *$ & $1.503,4^{*}$ & $1,38^{*}$ & $0,80^{*}$ & 0,86 & $0,77^{*}$ \\
\hline 10,0 & $3.030,3$ & $22.303,0^{*}$ & $2.718,7^{*}$ & $1,86^{*}$ & $0,74^{*}$ & 0,52 & $1,21^{*}$ \\
\hline 15,0 & $4.545,5$ & $15.045,5^{*}$ & $2.541,2^{*}$ & $2,58^{*}$ & $0,71 *$ & 0,50 & $1,76^{*}$ \\
\hline \multicolumn{8}{|c|}{$3^{\circ}$ CORTE } \\
\hline 0 (controle) & 0,0 & $1.124,2$ & 83,6 & 1,14 & 1,91 & 2,14 & 0,02 \\
\hline 1,5 & 454,5 & $6.036,4^{*}$ & $407,5^{*}$ & 1,04 & $1,30^{*}$ & $1,76^{*}$ & 0,11 \\
\hline 3,0 & 909,1 & $10.857,6^{*}$ & $744,8^{*}$ & 1,15 & $1,15^{*}$ & $1,28^{*}$ & $0,28 *$ \\
\hline 5,0 & $1.515,2$ & $11.175,8^{*}$ & $774,5^{*}$ & 1,05 & $1,29 *$ & $1,18^{*}$ & $0,74 *$ \\
\hline 10,0 & $3.030,3$ & $15.239,4^{*}$ & $1.245,1^{*}$ & $1,36^{*}$ & $0,90 *$ & 0,77 & $0,62 *$ \\
\hline 15,0 & $4.545,5$ & $16.484,9 *$ & $1.735,9 *$ & $1,61 *$ & $0,92 *$ & 0,91 & $0,68^{*}$ \\
\hline
\end{tabular}

* Em cada corte nas colunas as médias diferem do tratamento controle pelo teste de Dunnett a 5\% de probabilidade. 


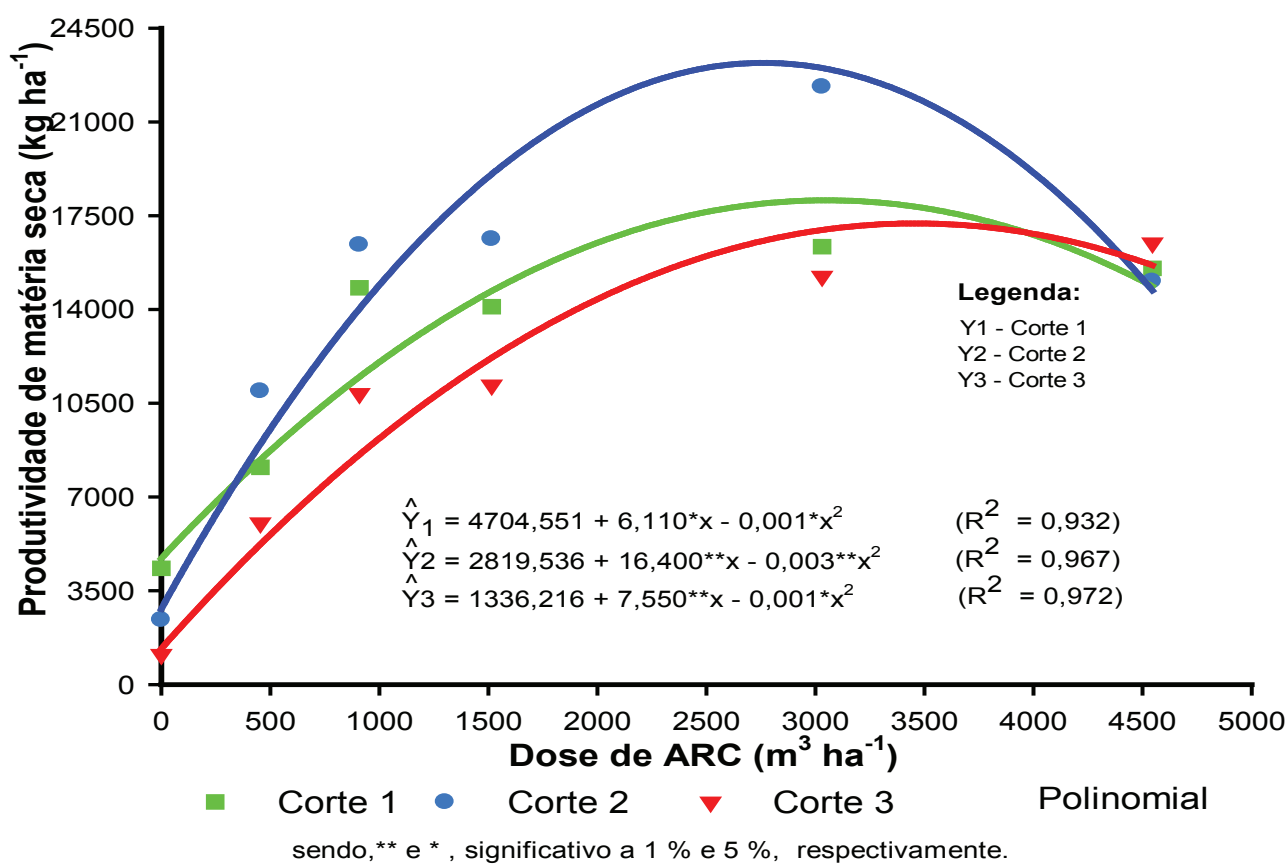

Figura 1. Produtividade de matéria seca, parte aérea do capim mombaça em três cortes em função da dose de aplicação da ARC.

A maior taxa de aplicação de ARC $\left(15 \mathrm{~kg} \mathrm{ha}^{-1}\right.$ de $\mathrm{Cr}$ ) proporcionou leve estresse nas plantas, o que ficou evidenciado pela redução na produtividade de matéria seca. Esse fato confirma o resultado do trabalho conduzido por Castilhos et al. (2001), que observaram redução de $36 \%$ na produtividade de matéria seca total das plantas de soja cultivadas sob doses crescentes de $\mathrm{Cr}^{3+}$. Entretanto, o possível efeito do crômio pode ter sido potencializado pelo maior aporte de sódio ao solo (Quadro 3), decorrente da aplicação das doses crescentes de ARC.

Matos et al. (2008), em estudo com capim tifton 85 cultivados em SACs, submetidos à aplicação de água residuária de laticínios, obtiveram uma produtividade estimada de $15,4 \mathrm{t} \mathrm{ha}^{-1}$ de matéria seca, para uma taxa de aplicação de água residuária de $469 \mathrm{~kg} \mathrm{ha}^{-1}$ de DBO. Fia et al. (2011) obtiveram produtividades de 5,9 e $6,8 \mathrm{t} \mathrm{ha}^{-1}$, no primeiro e segundo cortes, respectivamente, aplicando-se uma carga de $327 \mathrm{~kg} \mathrm{ha}^{-1} \mathrm{~d}^{-1}$ de DBO em SACs cultivados com capim tifton- 85 no tratamento de águas residuárias de suinocultura. Erthal et al. (2010) obtiveram 6,4 a $10 \mathrm{t} \mathrm{ha}^{-1}$ de matéria seca, quando fertirrigaram o capim tifton- 85 com água residuária de bovinocultura. No presente trabalho, a produtividade máxima estimada foi de 22,3 $\mathrm{t} \mathrm{ha}^{-1}$, portanto, bem acima dos valores anteriormente citados, o que pode estar relacionado às características do capim mombaça, à água residuária ou mesmo a fatores ligados à luminosidade.

A produtividade de proteína bruta do capim mombaça sofreu influência $(\mathrm{P}<0,05)$ da interação entre tratamentos e cortes. Os resultados apresentados no Quadro 4 indicaram que a produtividade de proteína bruta obtida nos tratamentos em que foi aplicada ARC em dose superior ou igual a 3,0 $\mathrm{kg} \mathrm{ha}^{-1}$ de $\mathrm{Cr}$ foi sempre superior à obtida no tratamento testemunha, em todos os cortes. Em termos de percentual de proteína bruta, os valores médios encontrados foram de 9,76\% para o capim que foi fertirrigado com ARC e 5,5\% para o capim que recebeu somente água da rede de abastecimento.

A produtividade de proteína bruta pelo capim mombaça quando nele foram aplicadas diferentes doses de $\mathrm{Cr}$, via ARC, está apresentada na Figura 2.

Conforme pode ser observado na Figura 2, verifica-se efeito positivo da ARC na produtividade de PB com o capim mombaça. 


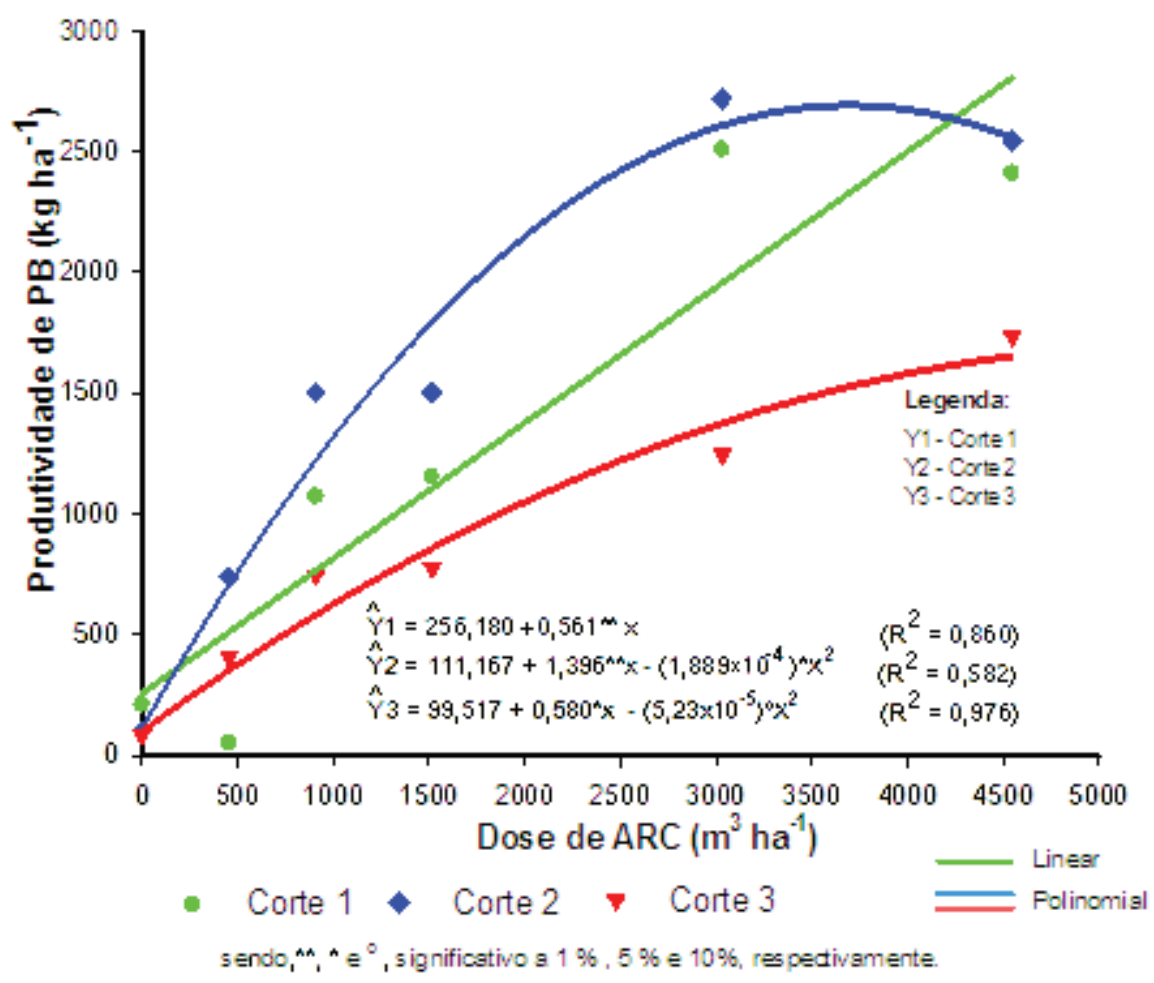

Figura 2. Produtividade de proteína bruta pelo capim mombaça submetido à aplicação de diferentes doses de $\mathrm{Cr}$, aplicadas via ARC.

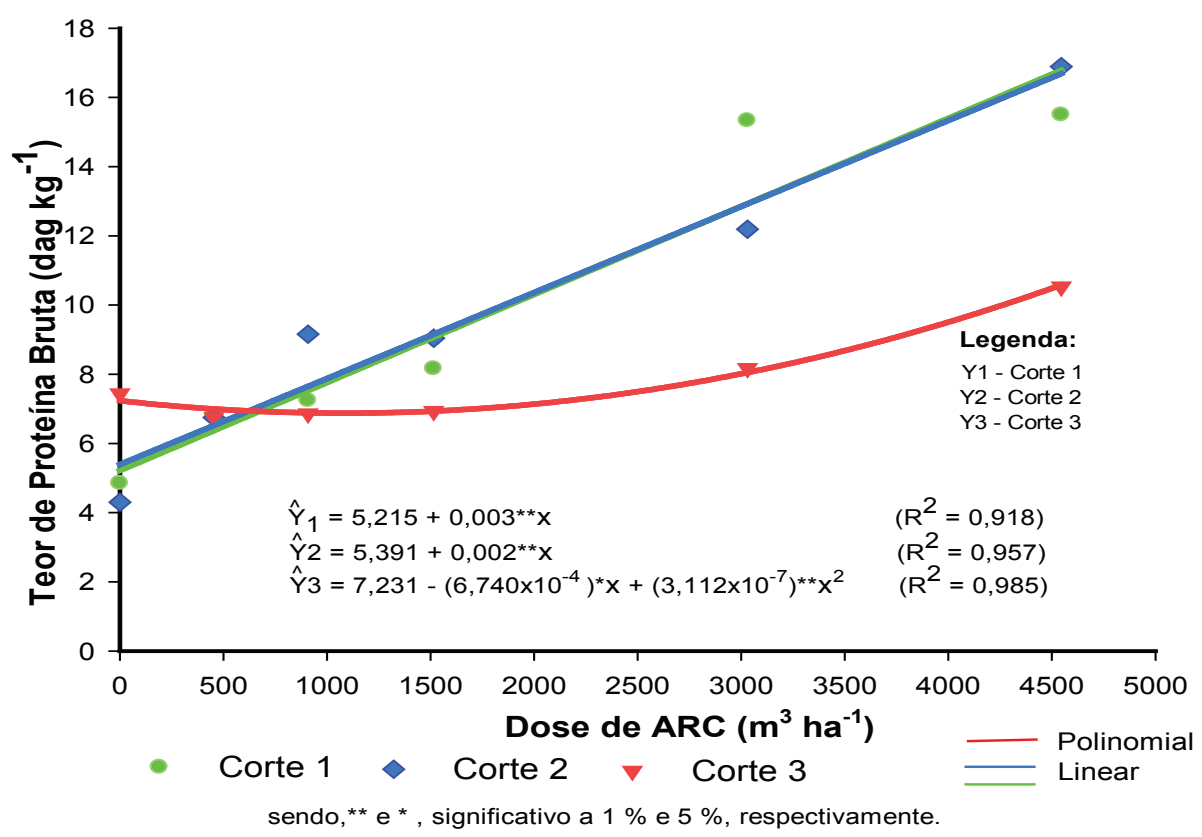

Figura 3. Teor de proteína bruta nas folhas do capim mombaça, em três cortes, em função da dose de ARC aplicada. 
Na Figura 3 estão apresentadas as curvas de teor de proteína bruta no capim mombaça como função das doses de $\mathrm{Cr}$ aplicadas via $\mathrm{ARC}$, tendo sido ajustados três modelos polinomiais de segundo grau para associação entre as referidas variáveis, um para cada corte do capim.

Com base nos valores obtidos nos três cortes, foi possível estabelecer uma relação quadrática entre os teores de PB e as doses de ARC aplicadas, havendo aumento nos teores de PB com o aumento na dose de ARC aplicada. $\mathrm{O}$ aumento no conteúdo de $\mathrm{PB}$ com a dose de $\mathrm{ARC}$ está associado à maior absorção de nitrogênio pelo capim, já que esses teores estão diretamente associados.

Sabe-se que os teores de PB inferiores a 7 dag $\mathrm{kg}^{-1}$ são limitantes à produção animal, trazendo, como consequência, menor consumo voluntário, redução na digestibilidade e balanço nitrogenado negativo (SILVA et al., 2009). Os teores obtidos de PB obtidos, neste trabalho, no primeiro e segundo cortes do capim mombaça ( 4 a $16 \mathrm{dag} \mathrm{kg}^{-1}$ ), foram semelhantes aos apresentados por Erthal et al. (2010), que obtiveram valores entre 6,4 a 14,8 dag $\mathrm{kg}^{-1}$ no capim Tifton 85 , aplicando água residuária da bovinocultura (ARB). No entanto, foram inferiores aos obtidos por Matos et al. (2008), que ao aplicarem taxas de carregamento orgânico de 66 a $570 \mathrm{~kg} \mathrm{ha}^{-1} \mathrm{~d}^{-1}$ de DBO de água residuária de laticínios (ARL) em SACs cultivados com capim tifton-85, obtiveram teores de PB de 18,1 a 25,0 dag $\mathrm{kg}^{-1}$ e por Fia et al. (2011), que obtiveram teores de $\mathrm{PB}$ de 28,$4 ; 27,0 ; 28,0 ; 29,2 \mathrm{dag} \mathrm{kg}^{-1}$, somatório de dois cortes de capim tifton-85 que recebeu taxas de carregamento de 163,$0 ; 327,0 ; 460,0 ; 561 \mathrm{~kg} \mathrm{ha}^{-1}$ $\mathrm{d}^{-1}$ de DBO, respectivamente, em SACs utilizados no tratamento de ARS.

Analisando-se ainda os dados apresentados na Figura 3, verificou-se decréscimo no teor de proteína bruta no terceiro corte. É amplamente reconhecido, na literatura pertinente, que o teor de PB de plantas forrageiras decresce com o aumento da idade, pois, ocorre diminuição na relação lâmina/haste e aumento da lignificação da parede celular da forragem. Segundo Rosa e Borges (1987), os teores de PB variam inversamente com a idade de planta, sendo este decréscimo explicado pelas alterações fisiológicas que caracterizam o desenvolvimento das mesmas, havendo mudanças no citoplasma das células com decréscimos nas concentrações de proteínas, lipídios e carboidratos solúveis. Por outro lado, Silva et al. (2009), em experimento realizado para caracterização e identificação das frações protéicas do capim mombaça, submetido a quatro doses de nitrogênio, com cortes efetuados no período seco e chuvoso, constataram que, quando a adubação nitrogenada é realizada no terço final do período chuvoso ocorre aumento nos teores médios de proteína bruta no capim. Constataram também que a dose de nitrogênio e a altura do corte influenciaram na composição das frações protéicas.

De acordo com os dados apresentados no Quadro 4, observa-se que, em relação aos macronutrientes $\mathrm{N}$ e $\mathrm{P}$, ocorreu, no geral, diferença significativa ( $\mathrm{P}$ $<0,05)$ entre os tratamentos, ou seja, entre as doses de ARC aplicadas. Verificou-se, também, que a aplicação da ARC proporcionou grande acúmulo de nitrogênio na planta e maior desenvolvimento do capim mombaça em todos os tratamentos, quando comparado ao obtido no tratamento testemunha (sem aplicação da ARC). Na Figura 4, está apresentado o detalhe do amarelecimento das folhas do capim mombaça que não recebeu a aplicação de $\mathrm{ARC}$, em decorrência da deficiência de nitrogênio, causando a clorose ou amarelecimento das folhas. Este amarelecimento começa primeiro nas folhas mais velhas, aparecendo, posteriormente, nas folhas jovens, à medida que a deficiência se torna mais severa. Silva (2010), em estudo realizado com o capim mombaça na região do Cerrado do Tocantins, verificou uma tendência de decréscimo na concentração de nitrogênio nas folhas do capim no último corte, o qual apontou como possível causa a maior velocidade de expansão foliar do capim no período de verão que, por conseguinte, proporcionou diluição da proteína bruta na folha.

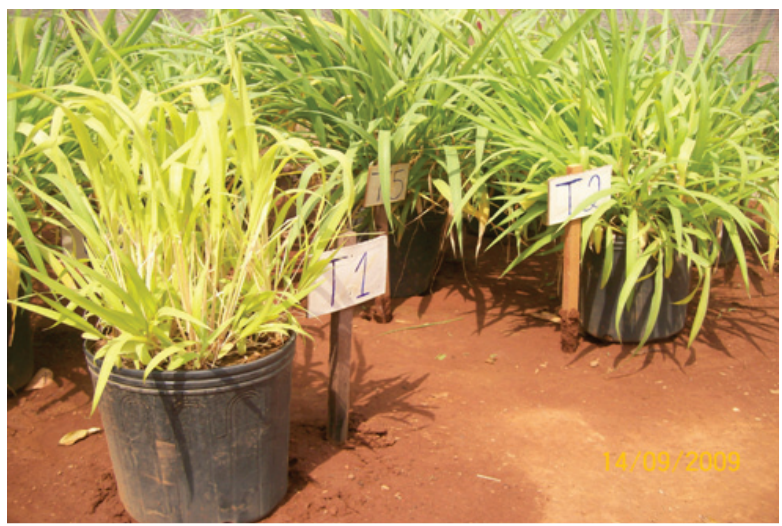

Figura 4. Detalhe da deficiência nutricional da planta que não recebeu água residuária. 
No capim que recebeu água residuária, os teores de $\mathrm{N}$ encontrados nas folhas estão acima dos valores reportados por Malavolta et al. (1997), que citam a faixa normal como sendo de 1,13 a 1,5 dag $\mathrm{kg}^{-1}$. Os valores mais altos, encontrados no presente trabalho (1,03 a 2,58 dag $\left.\mathrm{kg}^{-1}\right)$, podem estar relacionados à, relativamente, alta concentração de $\mathrm{N}$ na água residuária aplicada (Quadro 4).

$\mathrm{Na}$ análise foliar foram obtidos valores médios de concentração de $P$, que variaram de 0,65 a $1,91 \mathrm{dag}_{\mathrm{kg}^{-1}}$, aplicando-se doses variando de 0,9 a $8,8 \mathrm{~kg} \mathrm{ha}^{-1}$ de $\mathrm{P}$, via ARC . Esses valores foram superiores aos encontrados por Silva (2010) que, em estudo realizado com capim mombaça em iguais condições de clima e solo, porém, fertirrigado com esgoto doméstico, proporcionando dosagens de 11 a $44 \mathrm{~kg} \mathrm{ha}^{-1}$ de $\mathrm{P}$ no solo, obteve valores entre 0,35 a $1,78 \mathrm{dag} \cdot \mathrm{kg}^{-1}$ de $\mathrm{P}$ na parte aérea do capim. Os resultados também foram superiores aos encontrados Matos et al. (2008), Fia et al. (2011) e Erthal et al. (2010). Matos et al. (2008a) aplicando ARL, em SACs cultivados com capimtifton 85 , verificaram aumento na concentração de fósforo com o aumento nas taxas de carregamento orgânico superficial (TCOs) aplicadas. A menor TCOs (66 kg ha-1 ano ${ }^{-1}$ de $\mathrm{DBO}_{5}$ ) proporcionou a concentração de $0,32 \mathrm{dag} \mathrm{kg}^{-1} \mathrm{e}$ a maior $(570 \mathrm{~kg}$ ha $^{-1}$ ano $^{-1}$ de $\mathrm{DBO}_{5}$ ) a concentração de 0,41 dag $\mathrm{kg}^{-1}$. Fia et al. (2011), ao tratarem ARS em SACs cultivados com capim tifton-85, com cargas entre 162 e $607 \mathrm{~kg} \mathrm{ha}^{-1} \mathrm{~d}^{-1}$ de $\mathrm{DBO}_{5}$ e 6,2 a $23 \mathrm{~kg} \mathrm{ha}^{-1}$ de $\mathrm{P}$, obtiveram concentrações variando de 0,79 a $0,97 \mathrm{dag} \mathrm{kg}^{-1}$, em dois cortes realizados nas plantas. Erthal et al. (2010) obtiveram no primeiro corte da parte aérea do capim tifton concentrações variando de 0,17 a 0,19 dag kg $^{-1}$ de $\mathrm{P}$, quando o fertirrigaram com ARB, com taxas de aplicação de 25; 50, 75 e $100 \mathrm{~kg} \mathrm{ha}^{-1}$ de $\mathrm{K}$, correspondendo a 14,$5 ; 28,9$; 43,4 e 57,9 $\mathrm{kg} \mathrm{ha}^{-1}$ de $\mathrm{P}$.

Observando, ainda, dados apresentados no Quadro 4, constata-se que em todos os cortes, os valores de $P$ referentes ao tratamento controle foram superiores aos valores obtidos nos tratamentos que receberam doses crescentes de aplicação da ARC. Isto pode ter ocorrido em razão do tratamento controle não ter recebido grande aporte de sódio via ARC (Quadro 3), o que sabidamente pode comprometer a absorção de outros nutrientes.
De acordo com o que está apresentado na Quadro 4, as concentrações de $\mathrm{K}$ na folha do capim obtidas no primeiro e segundo cortes não variaram muito, não havendo, inclusive, diferença significativa em relação ao que foi obtido no tratamento testemunha. No terceiro corte, houve redução significativa em relação ao tratamento testemunha, alcançando-se a maior concentração $\left(1,76 \mathrm{dag} \mathrm{kg}^{-1}\right)$ quando foi aplicada a dose de $1,5 \mathrm{~kg}$ ha $^{-1}$ de Cr. Nota-se, tal como observado em relação ao fósforo, que os valores de $\mathrm{K}$ referentes ao tratamento controle foram superiores aos valores obtidos nos demais tratamentos. Além disso, nota-se que, nos três cortes, de um modo geral, o aumento da dose de ARC proporcionou valores decrescentes de potássio e crescentes de sódio no capim mombaça. Isso pode ter ocorrido em razão do elevado aporte de sódio ao solo (Quadro 3) nos tratamentos que receberam doses crescentes de ARC, o que pode ter comprometido a absorção de potássio pelas plantas e favorecido a absorção de sódio, presente em maior quantidade. Segundo Kawasaki et al. (1983), o aumento da concentração de sódio no meio radicular pode inibir a absorção de potássio devido à relação competitiva entre esses cátions monovalentes.

A explicação para a elevada concentração de sódio presente na ARC é a forma de tratamento para conservação das peles. Quando as peles do curtume precisam ser estocadas ou transportadas, devem ser conservadas, para evitar a proliferação de micro-organismos. Como no Estado do Tocantins a produção de pele é muito dispersa, estando geralmente longe dos curtumes, o produtor tem que aguardar por semanas para que o material seja recolhido e conduzido para processamento. Nesse caso, para se evitar a proliferação de microorganismos e, consequentemente, proporcionar maior conservação das peles, tem sido comum a realização da sua "cura", efetuada por meio da aplicação de grande quantidade de $\mathrm{NaCl}$ sobre elas. Assim, por ocasião do processamento, as peles terão que ser lavadas e, com isso, o efluente do processo torna-se muito rico em Na. Sendo o sódio muito solúvel e disponível no solo, as plantas o absorveram em grande quantidade.

A média dos valores de concentração de $\mathrm{K}$ na folha de capim encontrada no presente trabalho está

\section{REVENG}

173-186p. ENGENHARIA NA AGRICULTURA, VIÇOSA - MG, V.21 N.2, MARÇO / ABRIL 2013 
menor que a faixa considerada normal por Malavolta et al. (1997), que é de 1,43 a 1,84 dag kg-1.

Em relação à concentração de sódio na folha do capim, observou-se que todas as doses de ARC aplicadas (à exceção da de $1,5 \mathrm{~kg} \mathrm{ha}^{-1} \mathrm{de} \mathrm{Cr}$, no primeiro e terceiro cortes) proporcionaram aumento na concentração de sódio na folha do capim mombaça, em relação ao tratamento testemunha; em que o capim recebeu apenas água da rede de abastecimento (Quadro 4), tendo sido obtida uma relação linear com a dose aplicada. Silva et al. (2010) também observaram que, no capim tifton 85 , a concentração de sódio nas folhas aumentou linearmente com a taxa de aplicação do percolado de resíduo sólido urbano (RSU), sabidamente rico em sódio, tendo a concentração atingido o seu valor máximo $\left(0,25 \mathrm{dag} \cdot \mathrm{kg}^{-1}\right)$ no seu primeiro corte. No presente trabalho, a concentração máxima foi alcançada no segundo corte, com 1,76 dag $\cdot \mathrm{kg}^{-1}$, valor superior, tendo em vista a ARC apresentar alta concentração de $\mathrm{Na}\left(9.812 \mathrm{mg} \cdot \mathrm{L}^{-1}\right)$.

No Quadro 5 estão apresentados os teores médios, obtidos nas análises efetuadas no material vegetal obtido nos três cortes efetuados no capim, e os valores médios e estimados de remoção e estimados de $\mathrm{Cr}$ do solo. Para estimativa da remoção anual, considerou-se que a produtividade média obtida nos três cortes seja mantida ao longo do ano.

A concentração média Cr encontrada nas folhas do capim mombaça variou de 18,52 a $24,70 \mathrm{mg} \mathrm{kg}-$ ${ }^{1}$, valores superiores aos obtidos por Oliveira et al.
(2008) na parte aérea de capim-elefante, cultivado em área receptora de resíduos da indústria de couro.

Analisando-se os resultados obtidos, verificase que a concentração de $\mathrm{Cr}$ nas folhas do capim mombaça apresentou tendência de diminuição com a dose aplicada no solo. Atribui-se isso ao efeito de diluição provocado pela maior produção de massa seca, que seguiu tendência inversa, ou seja, de aumento com a dose aplicada. Esses resultados são indicativos de que o aumento da dose de $\mathrm{Cr}$ aplicada não proporcionou prejuízos à produtividade do capim e, ao contrário, em razão da disponibilização de maior quantidade de nutrientes, concorreu para que houvesse aumento na produtividade.

Os resultados obtidos contrariam o que foi obtido por Losi et al. (1994) que afirmaram que efeitos tóxicos do $\mathrm{Cr}$, na maioria das plantas, ocorrem quando as concentrações do elemento nas folhas é superior a $18 \mathrm{mg} \mathrm{kg}^{-1}$. Castilhos et al. (2001) observaram uma redução de 36\% na produção de matéria seca total das plantas de soja no tratamento com adição de $40 \mathrm{mg} \mathrm{L}^{-1}$ de $\mathrm{Cr}^{3+}$ na solução, sendo a concentração no tecido das plantas, nesse tratamento, igual a $19,8 \mathrm{mg} \mathrm{kg}^{-1}$. Os autores concluíram que teores de $\mathrm{Cr}$ na parte aérea de plantas de soja superiores à $5,8 \mathrm{mg} \mathrm{kg}^{-1}$ podem ser considerados fitotóxicos. No presente trabalho, as plantas não apresentaram sinais de intoxicação com $\mathrm{Cr}$, mesmo tendo alcançado valores de até $24,70 \mathrm{mg} \mathrm{kg}^{-1}$, entretanto, não se deve descartar a possibilidade de que sintomas possam aparecer

Quadro 5. Concentração média de Cr nas folhas do capim mombaça e quantidade removida, em três cortes, e estimada quando submetido a diferentes doses de aplicação de ARC

\begin{tabular}{cccc}
\hline $\begin{array}{c}\text { Tratamento } \\
\left(\mathrm{kg} \mathrm{ha}^{-1} \mathrm{de} \mathrm{Cr}\right)\end{array}$ & $\begin{array}{c}\text { Concentração média } \\
\text { na folha } \\
\left(\mathrm{mg} \mathrm{kg}^{-1}\right)\end{array}$ & $\begin{array}{c}\text { Removido pelas plantas } \\
\left(\mathrm{kg} \mathrm{ha}^{-1}\right)\end{array}$ & $\begin{array}{c}\text { Remoção estimada } \\
\left(\mathrm{kg} \mathrm{ha}^{-1} \mathrm{ano}^{-1}\right)\end{array}$ \\
\hline 0,0 & $24,70 \pm 11,85$ & 0,065 & 0,264 \\
1,5 & $23,38 \pm 15,26$ & 0,196 & 0,795 \\
3,0 & $23,70 \pm 13,63$ & 0,332 & 1,346 \\
5,0 & $12,50 \pm 12,99$ & 0,175 & 0,548 \\
10,0 & $17,89 \pm 11,52$ & 0,321 & 1,302 \\
15,0 & $18,52 \pm 14,17$ & 0,291 & 1,180 \\
\hline
\end{tabular}


caso a experimentação fosse realizada por maior período de tempo. Jeevan Rao e Shantaran (1996) afirmam que o acúmulo de metais pesados nas plantas pode ocorrer sem que haja manifestação de sintomas de toxicidade e prejuízo para a produção das culturas, entretanto, poderá interferir na qualidade dos alimentos, conforme verificado por Santos et al. (2002).

Pereira et al. (2010) realizaram estudos objetivando avaliar os teores de metais pesados ( $\mathrm{Cd}, \mathrm{Pb}, \mathrm{Cu}, \mathrm{Cr}, \mathrm{Fe}, \mathrm{Mn}$, Ni e $\mathrm{Zn}$ ) em folhas de Brachiaria decumbens Stapf., em áreas sob influência de rodovias com diferentes fluxos de veículos e em uma área testemunha, no Estado de Goiás e constataram que os valores encontrados não caracterizaram contaminação ambiental, especificamente para o $\mathrm{Cr}$, o valor máximo encontrado foi de $0,23 \mathrm{mg} \cdot \mathrm{dm}^{-3}$. Ramos e Geraldo (2007), ao analisarem a concentração de crômio na parte aérea de plantas em desenvolvimento na área de mangues, encontraram valores de 2,05 a $8,2 \mathrm{mg} \cdot \mathrm{kg}^{-1}$. Aquino Neto e Camargo (2000) encontraram concentrações de até $8,81 \mathrm{mg} \cdot \mathrm{kg}^{-1}$ nas folhas de alface adubado com lodo de esgoto na dose aplicada de $57 \mathrm{t} \cdot \mathrm{ha}^{-1}$.

As taxas de extração de Cr pelas plantas foram variáveis, não apresentando tendência clara em relação à dose de $\mathrm{Cr}$ aplicada ao solo, entretanto aumentou em relação à concentração nas folhas do capim, no tratamento testemunha.

\section{CONCLUSÃO}

De acordo com os resultados obtidos, pôde-se concluir que:

- O capim mombaça demonstrou boa persistência, alta capacidade de extração de nutrientes, alta produção de matéria seca, o que permitiu cortes frequentes e sucessivos ao longo do ano, boa adaptação às condições de clima do estado do Tocantins e também tolerância à toxicidade de íons específicos;

- A aplicação da água residuária foi responsável pelo aumento no teor de proteína bruta do capim nos dois primeiros cortes e também na produtividade de matéria seca. Tanto a produtividade de matéria seca como a de proteína bruta foram maiores no corte 2, alcançando-se os maiores valores quando da aplicação das doses estimadas de 2.734 e 3.055 $\mathrm{m}^{3} \mathrm{ha}^{-1}$ de ARC, respectivamente.

- A concentração de $\mathrm{P}$ nas folhas do capim mombaça diminuiu com a aplicação da ARC;

- Aumento na dose de ARC proporcionou decréscimo na concentração de potássio e aumento na de sódio nas folhas do capim mombaça;

- Não foi observada influência das doses de ARC na concentração de crômio nas folhas do capim mombaça. Com base no que foi exposto, doses de até $15 \mathrm{~kg} \mathrm{ha}^{-1}$ ano $^{-1}$ de $\mathrm{Cr}$ proporcionaram reduzido risco de contaminação ambiental, recomendando-se, no entanto, monitoramento da concentração acumulada de $\mathrm{Cr}$ no solo.

- No caso específico da água residuária estudada, em vista de se utilizar muito $\mathrm{NaCl}$ na salga das peles, o aumento da concentração de sódio nas plantas é aparentemente problema maior do que propriamente do crômio.

\section{REFERÊNCIAS BIBLIOGRÁFICAS}

APHA - American Public Health Association; AWWA - American Water Works Association; WEF - Water Environment Federation. Standard methods for the examination of water and wastewater. 21.ed. Washington: APHA/AWWA/ WEF, 2005. 1268p.

AQUINO NETO, V.; CAMARGO, A. Crescimento e acúmulo de crômio em alface cultivada em dois Latossolos tratados com $\mathrm{CrCl}_{3}$ e resíduo de curtume. Revista Brasileira de Ciência do Solo, Viçosa, v.24, p.225-235, 2000.

CASTILHOS, D.D.; GUADAGNIN, C.A.; SILVA, M.D.; LEITZKE, V.W.; FERREIRA, L.H.; NUNES, M.C. Acúmulo de cromo e seus efeitos na fixação biológica de nitrogênio e absorção de nutrientes em soja. Revista Brasileira de Agrociência, Pelotas, v.7 n. 2, p. 121-124, 2001.

CONCEIÇÃO, D.; RODRIGO, J.; BENTO, F.; SIMONETTI, A.; SELBACH, P.; CAMARGO, 
F. Redução de cromo hexavalente por bactérias isoladas de solos contaminados com cromo. Revista Ciência Rural, Santa Maria, RS, v.37, n.6, p.1661-1667, 2007.

EMPRESA BRASILEIRA DE PESQUISA AGROPECUÁRIA-EMBRAPA. Centro Nacional de Pesquisa de Solos. Manual de métodos de análises de solo. 2.ed. Rio de Janeiro, 1997. 212 p.

ERTHAL, V.J.T.; FERREIRA, P.A.; PEREIRA, O.G.; MATOS, A.T. Características fisiológicas, nutricionais e rendimento de forrageiras fertigadas com água residuária de bovinocultura. Revista Brasileira de Engenharia Agrícola e Ambiental, Campina Grande, v.14, n.05, p. 458-466, 2010.

FACHIN, S.J.S.; HUBER, F.; SHIRAIWA, S.; BORGES, W.R.; MIGLIORINI, R.B. Aplicação de métodos geofísicos para identificar áreas contaminadas por resíduos de um curtume. Revista Brasileira de Geofísica, São Paulo, SP, v.24, n.1, 2006.

FIA, F. R. L.; MATOS, A. T.; FIA, R.; LAMBERT, T. F.; MATOS, M. P. Remoção de nutrientes por Typha latifólia e Cynodon spp. Cultivadas em sistemas alagados contruídos. Ambi-água, Taubaté, v.6, n.1, p.77-89, 2011.

GARCIA, C.S.; FERNANDES, A.M.; FONTES, C.A.A.; VIEIRA, R.A.M.; SANT'ANNA, N.F.; PIMENTEL, V.A. Desempenho de novilhos mantidos em pastagens de capim-elefante e capimmombaça. Revista Brasileira de Zootecnia, Viçosa, v.40, n.2, p.403-410, 2011.

JEEVAN RAO, K.; SHANTARAM, M.V. Effect of urban solid wastes on dry matter yield, uptake of micronutrients and heavy metals by maize plants. Journal Environmental Biology, Muzaffarnagar, v.17, n.1, p.25-32, 1996.

JORDÃO, C.P.; SILVA, A.C.; PEREIRA, J.L.; BRUNE, W. Contaminação por crômio de águas de rios proveniente de curtumes em Minas Gerais. Revista Química Nova, São Paulo, v. 22, p. 47-52, 1999.
KAWASAKI, T.; AKIBA, T.; MORITSUGU, M. Effects of high concentrations of sodium chloride and polyethylene glycol on the growth and ion absorption in plants: I. Water culture experiments in a greenhouse. Plant and Soil, Dordrecht, v.75, p.75-85, 1983.

KIEHL E. J. Fertilizantes orgânicos. São Paulo: Agronômica Ceres, 1998. 326p.

LO MONACO, P.A.V.; MATOS, A.T.; MARTINEZ, H.E.P.; FERREIRA, P.A.; RAMOS, M.M. Características químicas do solo após a fertirrigação do cafeeiro com águas residuárias da lavagem e descascamento de seus frutos. Irriga, Botucatu, v.14, n.3, p.348-364, 2009.

LOSI, M.E.; AMRHEIN, C.; FRANKENBERGER, W.T. Environmental biochemistry of chromium. Reviews of Environmental Contamination and Toxicology, New York, v.135, p.91-121, 1994.

MALAVOLTA, E.; VITTI, G.; OLIVEIRA, S.A. Avaliação do estado nutricional de plantas: princípios e aplicações. 2.ed. Piracicaba: Associação Brasileira para Pesquisa da Potassa e do Fósforo-Potafós, 1997. 319 p.

MATOS, A.T.; ABRAHÃO, S.S.; PEREIRA, O.G. Desempenho agronômico de capim tifton 85 (cynodon spp) cultivado em sistemas alagados construídos utilizados no tratamento de água residuária de laticínios. Ambi-Água, Taubaté, v. 3, n. 1, p. 43-53, 2008.

MENEGATTI, D.P.; ROCHA, G.P.; FURTINI NETO, A.E.; MUNIZ, J.A. Nitrogênio na produção de matéria seca, teor e rendimento de proteína bruta de três gramíneas do gênero Cynodon. Ciência Agrotecnologia, Lavras, v. 26, n. 3, p. 633-642, 2002.

MINGOTTE, F.L.C.; SANTOS, C.L.R.; PRADO, R.M.; FLORES, R.A.; TOGORO, A.D.; SILVA, J.A.S.; POLITI, L.S.; PINTO, A.S.; AQUINO, D.S. Manganês na nutrição e na produção de massa seca do capim-mombaça. Bioscence Jounal, Uberlândia, v. 27, n. 6, p. 879-887, 2011. 
MÜLLER, M.S.; FANCELLI, A.L.; DOURADO NETO, D.; GARCIA, A.G.; OVEJERO, R.F.L. Produtividade do panicum maximum cv. mombaça irrigado, sob pastejo rotacionado. Scientia Agricola, Piracicaba, SP, v. 59, n. 3, p. 427-433, 2002.

OLIVEIRA， D.Q.L.; CARVALHO， K.T.G.; BASTOS, A.R.R.; OLIVEIRA, L.C.A.; MARQUES, J.J.G.S.M.; NASCIMENTO, R.S.M.P. Utilização de resíduos da indústria de couro como fonte nitrogenada para o capimelefante. Revista Brasileira de Ciência do Solo, Viçosa, v. 32, n. 1, 2008.

PEREIRA, A.A.; BORGES, J.D.; LEANDRO, W.M. Metais pesados e micronutrientes no solo e em folhas de Brachiaria decumbens às margens de rodovias. Bioscience Journal, Uberlândia, v. 26, n. 3, p. 347-357, 2010.

RAMOS, M.G.M.; GERALDO, L.P. Avaliação das espécies de plantas avicennia schaueriana, laguncularia racemosa e rhizophora mangle como bioindicadoras de poluição por metais pesados em ambientes de mangues. Engenharia Sanitária e Ambiental, Rio de Janeiro, v. 12, n. 4, p. 440-445, 2007.

ROSA, B.; BORGES, A.J.S. Composição química e rendimento do capim andropogon (Andropogon gayanus var. bisquamulatus cv. Planaltina) em diferentes idades de corte. Anais Escola de Agronomia e Veterinária, v. 17, n. 1, p. 49-58, 1987.
RIBEIRO, E.G.; FONTES, C.A.A.; PALIERAQUI, J.G.B.; CÓSER, A.C.; MARTINS, C.E.; SILVA, R.C. Influência da irrigação, nas épocas seca e chuvosa, na produção e composição química dos capins napier e mombaça em sistema de lotação intermitente. Revista Brasileira de Zootecnia, Viçosa, v.38, n.8, p.1432-1442, 2009.

SANTOS, F.S.; AMARAL SOBRINHO, N.M.B.; MAZUR, N. Influência de diferentes manejos agrícolas na distribuição de metais pesados no solo e em plantas de tomate. Revista Brasileira de Ciência do Solo, Viçosa, v. 26, p.535-543, 2002.

SILVA, J.G.D. Fertirrigação do capim-mombaça com diferentes lâminas de efluente de tratamento primário de esgoto sanitário estabelecidas com base na dose aplicada de sódio. 2010. $77 \mathrm{f}$. Dissertação (Mestrado em Engenharia Agrícola) Universidade Federal de Viçosa, Viçosa, MG.

SILVA, A.G.; FRANÇA, A.F.S.; MIYAGI, E.S.; MELLO, S.Q.S.; FERREIRA, J.L.; CARVALHO, E.R. Frações protéicas do capim-mombaça submetido a doses de nitrogênio em duas alturas de corte. Revista Brasileira de Medicina Veterinária e Zootecnia, Goiânia, v. 61, n. 5, p. 1148-1155, 2009.

SILVA, D.F.; MATOS, A.T.; PEREIRA, O.G.; CECON, P.R.; MOREIRA, D.A. Disponibilidade de sódio em solo com capim tifton e aplicação de percolado de resíduo sólido. Revista Brasileira de Engenharia Agrícola e Ambiental, Campina Grande, v.14, n.10, p.1094-1100, 2010. 